\title{
Design of Armature and Field Control Systems based Bacterial Foraging Optimization Technique for Speed Control of DC Motor
}

\author{
Wisam Najm Al-Din Abed \\ Electronic Department, Engineering College, University of Diyala, Iraq \\ wisam_alobaidee@yahoo.com
}

\begin{abstract}
The aim of this work is to design and simulate an armature and field control systems using state feedback controller based on bacterial foraging optimization (BFO) technique for controlling the speed of separately excited dc motor (SEDM). The controller's performances have been optimized based on social foraging behavior of Escherichia (E. Coli) bacteria. The state feedback controller's parameters (controller's gains $K_{1} \& K_{2}$ ) are tuned using foraging strategy. The SEDM is loading for different loads ranging from no-load to full-load to test the controller behavior and robustness for wide range of loadings variations. First the SEDM is simulated feeding back the armature current and angular speed (armature control method), second the SEDM is simulated with feeding back the field current and angular speed (field control method). For both controlling methods the controller's gains are tuned using BFO.
\end{abstract}

Keywords: Armature and Field Control Methods, Bacterial Foraging Optimization (BFO), Separately Excited DC Motor (SEDM), State Feedback

\section{Introduction}

The DC motor has been popular in the industry control area for a long time, because they have many good characteristics for example: high start torque characteristics, high response performance and easier to be linear control. DC motor has a good speed control respond, wide speed control range. And it is widely used in speed control systems which need high control requirements, such as rolling mill, double- hulled tanker, and high precision digital tools etc., [1].

During the last four decades, state feedback notion has attracted the attention of numerous researchers and has been very widely used in many control strategies. Due to the easiness of the control principle and its implementation, several methods were proposed to put some control strategies under a state feedback, as for example, predictive control, adaptive control, sliding mode control and high gain control. As high gain controller is computationally efficient, many works were proposed to put such control strategy under state feedback form [2]. The speed of DC motor can be adjusted to a great extent as to provide controllability easy and high performance. The controllers of the speed that are conceived for goal to control the speed of DC motor to execute one variety of tasks, is of several conventional and numeric controller types. Fuzzy Logic (FL) was invented in 1970s, which was powerful tool in the field of control applications. The Fuzzy controller gives superior performance over the conventional control methods such as PID controllers even if the accurate mathematical model is not available. Nowadays, several new intelligent optimization techniques have been emerged like: Genetic Algorithm (GA), Ant Colony Optimization (ACO), Simulated Annealing (SA), Bacterial Foraging (BF), and Particle Swarm Optimization (PSO) [1]. 


\section{Mathematical Model of Separately Excited d.c. Motor}

In a separately excited dc motor, the field coil is supplied from a different voltage source than that of the armature coil. The field circuit normally incorporates a rheostat through which the field current, and thus the motors characteristics, can be externally controlled. This motor is mainly suitable for two types of loads; those that require constant torque for speed variations up to full-load speed, and those whose power requirements are constant for speed variations above nominal speed [3].

The characteristic equations of the DC motor are represented as,

$\frac{\mathrm{di}_{\mathrm{a}}}{\mathrm{dt}}=\frac{1}{L_{a}}\left(V_{a}-R_{a} i_{a}-E\right)$

$\frac{\mathrm{di}_{\mathrm{f}}}{\mathrm{dt}}=\frac{1}{L_{f}}\left(V_{f}-R_{f} i_{f}\right)$

$\frac{\mathrm{d} \omega}{\mathrm{dt}}=\frac{1}{J}\left(T_{e}-T_{L}-B \omega\right)$

Where the $T_{e}$ is the development electrical torque, $E$ is the back EMF, B denotes the viscous friction coefficient, and $\mathrm{J}$ is the moment of inertial [4]. The armature circuit consists of an inductor $L_{a}$ and resistor $R_{a}$ in series with a counter electromotive force which is proportional to the DC motor speed [5].

$E=K_{E} \omega$

$K_{E}$ is the voltage constant and $\omega$ is the machine angular speed. In a separately excited DC machine model, the voltage constant $K_{E}$ is proportional to the field current $\left(I_{f}\right)$ as in (5).

$K_{E}=L_{a f} I_{f}$

Where $L_{a f}$ is the field armature mutual inductance. The electromechanical torque (Te) developed by the DC machine is proportional to the armature current $\left(I_{a}\right)$ as in (6).

$T_{e}=K_{T} I_{a}$

Where $K_{T}$ is the torque constant. In the SI unit, the torque and voltage constants are equal as in (7).

$K_{T}=K_{E}$

\section{Bacterial Foraging Optimization}

The Bacterial Foraging Optimization (Passino 2002) is based on foraging strategy of $E$. coli bacteria. The foraging theory is based on the assumption that animals obtain maximum energy nutrients ' $E$ ' in a suppose to be a small time ' $T$ '. The basic Bacterial Foraging Optimization consists of three principal mechanisms; namely chemotaxis, reproduction and elimination-dispersal. The brief descriptions of these steps involved in Bacterial Foraging are presented below [6]. To define our optimization model of E. coli bacterial foraging, we need to define a population (set) of bacteria, and then model how they execute chemotaxis, swarming, reproduction, and elimination/dispersal. After doing this, we will highlight the limitations (inaccuracies) in our model [7].

\subsection{Chemotaxis}

The movement of E. coli bacteria in the human intestine in search of nutrient-rich location away from noxious environment is accomplished with the help of the locomotory organelles known as flagella by chemotactic movement in either of the ways, that is, swimming (in the same direction as the previous step) or tumbling (in an absolutely different direction from the previous one). Suppose $\theta^{i}(j, k, \ell)$ represents the $i$ th bacterium at $j$ th chemotactic, $k$ th reproductive, and $\ell$ th elimination-dispersal step. Then chemotactic movement of the bacterium may be mathematically represented by Equation (8). In the 
expression, $C(i)$ is the size of the unit step taken in the random direction, and $\Delta(i)$ indicates a vector in the arbitrary direction whose elements lie in $[-1,1]$ as follows:

$\theta^{\mathrm{i}}(\mathrm{j}+1, \mathrm{k}, \ell)=\theta^{\mathrm{i}}(\mathrm{j}, \mathrm{k}, \ell)+\mathrm{C}(\mathrm{i}) \frac{\Delta(i)}{\sqrt{\Delta^{T}(i) \Delta(i)}}$

\subsection{Swarming}

This group behavior is seen in several motile species of bacteria, where the cells, when stimulated by a high level of succinate, release an attractant a spertate. This helps them propagate collectively as concentric patterns of swarms with high bacterial density while moving up in the nutrient gradient. The cell-to-cell signaling in bacterial swarm via attractant and repellant may be modeled by Equation (9), where $J_{c c}(\theta(i, j, k, \ell))$ specifies the objective function value to be added to the actual objective function that needs to be optimized, to present a time varying objective function, $S$ indicates the total number of bacteria in the population, $p$ is the number of variables to be optimized, and $\theta=\left[\theta_{1}, \theta_{2}, \ldots\right.$ ,$\left.\theta_{\mathrm{p}}\right]^{\mathrm{T}}$ is a point in the p-dimensional search domain. The coefficients dattractant,wattractant, hrepellant, and wrepellant are the measure of quantity and diffusion rate of the attractant signal and the repellant effect magnitude, respectively [8],

$\mathrm{J}_{\mathrm{cc}}(\theta(\mathrm{i}, \mathrm{j}, \mathrm{k}, \ell))=\sum_{i=1}^{S} \mathrm{~J}_{\mathrm{cc}}^{\mathrm{i}}\left(\theta, \theta^{\mathrm{i}}(\mathrm{j}, \mathrm{k}, \ell)\right)=\sum_{i=1}^{S}\left[-d_{\text {attract }} \exp \left(-w_{\text {attract }} \sum_{m=1}^{p}\left(\theta_{\mathrm{m}}-\right.\right.\right.$ $\left.\left.\left.\theta_{\mathrm{m}}^{\mathrm{i}}\right)^{2}\right)\right]+\sum_{i=1}^{S}\left[-h_{\text {repellant }} \exp \left(-w_{\text {repellant }} \sum_{m=1}^{p}\left(\theta_{\mathrm{m}}-\theta_{\mathrm{m}}^{\mathrm{i}}\right)^{2}\right)\right]$

\subsection{Reproduction}

For every $\mathrm{N}_{\mathrm{c}}$ times of chemotactic steps, a reproduction step is taken in the bacteria population. The bacteria are sorted in descending order by their nutrient obtained in the previous chemotactic processes. Bacteria in the first half of the population are regarded as having obtained sufficient nutrients so that they will reproduce. Each of them splits into two (duplicate one copy in the same location). Bacteria in the residual half of the population die and they are removed out from the population. The population size remains the same after this procedure. Reproduction is the simulation of the natural reproduction phenomenon. By this operator, individuals with higher nutrient are survived and duplicated, which guarantees that the potential optimal areas are searched more carefully [9]. The fitness value for $i$ th bacterium after travelling $N_{c}$ chemotactic steps can be evaluated by the following equation:

$\mathrm{J}_{\text {health }}^{\mathrm{i}}=\sum_{j=1}^{N_{c}+1} \mathrm{~J}(\mathrm{j}, \mathrm{k}, \ell)$

Here $\mathrm{J}_{\text {health }}^{\mathrm{i}}$ represents the health of ith bacterium. The least healthy bacteria constituting half of the bacterial population are eventually eliminated while each of the healthier bacteria asexually split into two, which are then placed in the same location. Hence, ultimately the population remains constant [8].

\subsection{Eliminate and Dispersal}

In nature, the changes of environment where population lives may affect the behaviors of the population. For example, the sudden change of temperature or nutrient concentration, the flow of water, all these may cause bacteria in the population to die or move to another place. To simulate this phenomenon, eliminate-dispersal is added in the BFO algorithm. After every $N_{\text {re }}$ times of reproduction steps, an eliminate-dispersal event happens. For each bacterium, a random number is generated between 0 and 1 . If the random number is less than a predetermined parameter, known as $P_{e}$, the bacterium will be eliminated and a new bacterium is generated in the environment. The operator can be also regarded as moving the bacterium to a randomly produced position. The eliminate- 
dispersal events may destroy the chemotactic progress. But they may also promote the solutions since dispersal might place the bacteria in better positions. Overall, contrary to the reproduction, this operator enhances the diversity of the algorithm [9].

\section{Simulation and Results}

A mathematical model of SEDM is simulated using MATLAB toolbox based on it's dynamic electrical and mechanical equations. Two control methods are designed; the first one is armature control method with feeding back the armature current $\left(\mathrm{I}_{\mathrm{a}}\right)$ and motor angular speed $(\infty)$ as a state variables that must be measured; and the second is field control method with feeding back the field current $\left(\mathrm{I}_{\mathrm{f}}\right)$ and motor angular speed $(\varpi)$ as a state variables that must be measured.

For armature control method; the state variables are sensed and adjusted using appropriate state feedback controller gains $\left(\mathrm{K}_{1}\right.$ and $\left.\mathrm{K}_{2}\right)$. The armature voltage source is changed based on control signal for adjusting the motor speed and keeping the field voltage source constant.

While for field control method; the state variables are also sensed and adjusted using appropriate state feedback controller gains $\left(\mathrm{K}_{1}\right.$ and $\left.\mathrm{K}_{2}\right)$. The field voltage source is changed based on control signal for adjusting the motor speed and keeping the armature voltage source constant. The SEDM are loaded at different loads ranging from no-load to full-load for checking the controller's performance and robustness for load variations.

\subsection{Design Requirements}

Since the most basic requirements of a motor are that it should rotate at the desired speed, the steady-state error $e_{s s}$ of the motor speed should be less than $5 \%$ of the normal speed (183.2596 radian/second), so the acceptable change in speed is ( $\mp 9.1630$ radian/second) so the acceptable speed limit between (192.4226 and 174.0966 radian/second), the settling time $T_{s}$ criterion should be less than $0.2 \mathrm{sec}$, percent overshoot less than $30 \%$ means the maximum acceptable speed is (238.2375 radian/second).

The SEDM are loaded for four different loads (assumed). These loads are: (no-load, light load ( 0.2 of full-load), half full load ( 0.5 of full-load), and full-load). The parameters values of SEDM used in the simulation is taken from MATLAB/Toolbox and shown in Table 1.

\section{Table 1. SEDM Parameters}

\begin{tabular}{|l|c|}
\hline Motor ratings and parameters & values \\
\hline Power & $200 \mathrm{HP}$ \\
\hline Armature voltage & $500 \mathrm{~V}$ \\
\hline Speed & 183.2596 radian/second \\
\hline Field voltage $\left(\mathrm{V}_{\mathrm{f}}\right)$ & $300 \mathrm{~V}$ \\
\hline Armature resistance $\left(\mathrm{R}_{\mathrm{a}}\right)$ & $0.08652 \Omega$ \\
\hline Armature inductance $\left(\mathrm{L}_{\mathrm{a}}\right)$ & $0.002118 \mathrm{H}$ \\
\hline Field resistance $\left(\mathrm{R}_{\mathrm{f}}\right)$ & $36.59 \Omega$ \\
\hline Field inductance $\left(\mathrm{L}_{\mathrm{f}}\right)$ & $3.896 \mathrm{H}$ \\
\hline $\mathrm{L}_{\mathrm{a}}$ & $0.314 \mathrm{H}$ \\
\hline Inertia of the rotor $(\mathrm{J})$ & $0.8159 \mathrm{Kg} . \mathrm{m}^{2}$ \\
\hline damping coefficient $(\mathrm{B})$ & $0.02063 \mathrm{~N} . \mathrm{m} . \mathrm{s}$ \\
\hline
\end{tabular}




\subsection{Simulation of SEDM using matlab/simulink}

The proposed mathematical model is developed from the mechanical and electrical dynamic equations of the SEDM (Equations (1-7)). Figure 1 and Figure 2, show the complete closed loop simulink model of SEDM with state feedback controllers for armature and field control methods respectively.

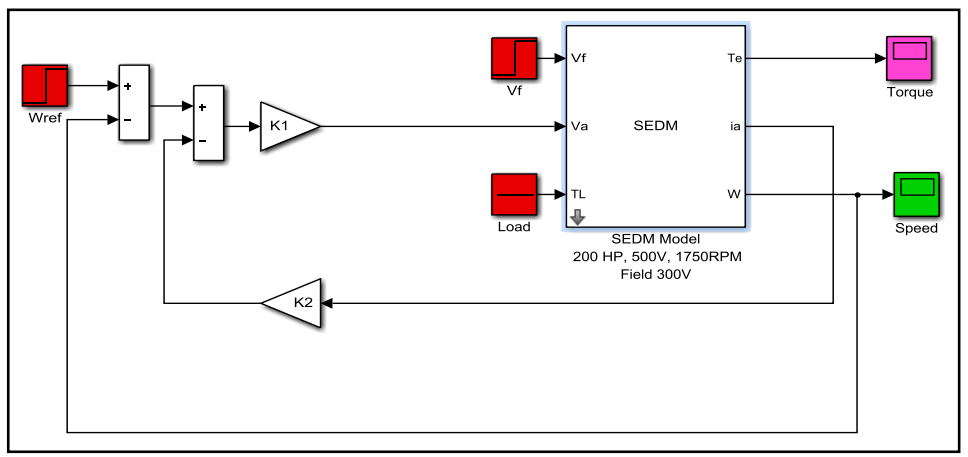

Figure 1. Armature Control System of SEDM with State Feedback Controller

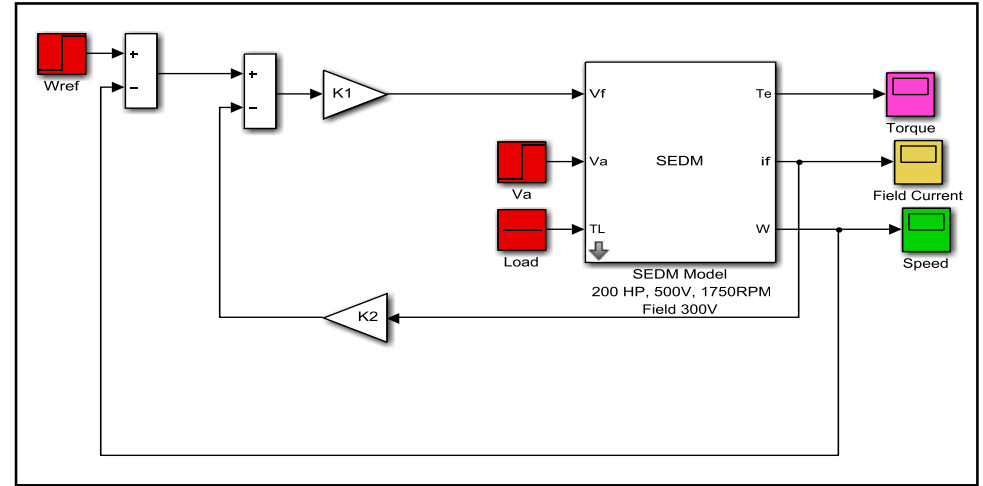

Figure 2. Field Control System of SEDM with State Feedback Controller

The parameters of BFO algorithm are listed in Table 2, for both control methods, while the obtained controller's parameters are listed in Table 3.

Table 2. BFO Parameters used in Tuning State Feedback Controller

\begin{tabular}{|l|c|c|}
\hline & Armature control & Field control \\
\hline BFO parameters & Parameters values & Parameters values \\
\hline Number of bacteria in the population $(\mathrm{s})$ & 20 & 20 \\
\hline The length of swim $\left(\mathrm{N}_{\mathrm{s}}\right)$ & 2 & 2 \\
\hline Number of reproduction steps $\left(\mathrm{N}_{\mathrm{re}}\right)$ & 4 & 4 \\
\hline Number of chemotactic step $\left(\mathrm{N}_{\mathrm{c}}\right)$ & 20 & 10 \\
\hline Number of elimination/dispersal events $\left(\mathrm{N}_{\mathrm{ed}}\right)$ & 2 & 2 \\
\hline Number of bacteria splits per generation $\left(\mathrm{S}_{\mathrm{r}}\right)$ & $\mathrm{s} / 2$ & $\mathrm{~s} / 2$ \\
\hline Probability of dispersal occurrence $\left(\mathrm{P}_{\text {ed }}\right)$ & 0.25 & 0.25 \\
\hline Hight of repellent effect $\left(\mathrm{h}_{\text {rep. }}\right)$ & 0.1 & 0.1 \\
\hline Width of repellent effect $\left(\mathrm{w}_{\text {rep. }}\right)$ & 10 & 10 \\
\hline Width of attractant effect $\left(\mathrm{w}_{\text {attr }}\right)$ & 0.2 & 0.2 \\
\hline Hight of attractant effect $\left(\mathrm{d}_{\text {attr. }}\right)$ & 0.1 & 0.1 \\
\hline
\end{tabular}


Table 3. State Feedback Controller's Parameters

\begin{tabular}{|c|c|c|}
\hline Controller parameters & Armature control method & Field control method \\
\hline $\mathrm{K}_{1}$ & 2380.00947 & 12.96289 \\
\hline $\mathrm{K}_{2}$ & 0.00088 & 12.97725 \\
\hline
\end{tabular}

Figure 3, and Figure 4, shows the bacteria $(S=10)$ motility behavior (bacteria trajectories) and the average cost plots for each generation for two elimination/dispersal events $(\mathrm{Ned}=2)$ for tuning the controller parameters for the armature and field control methods respectively.

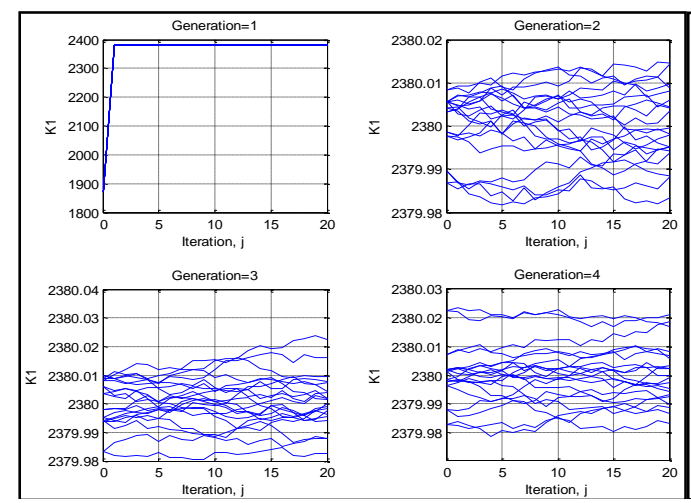

(a)
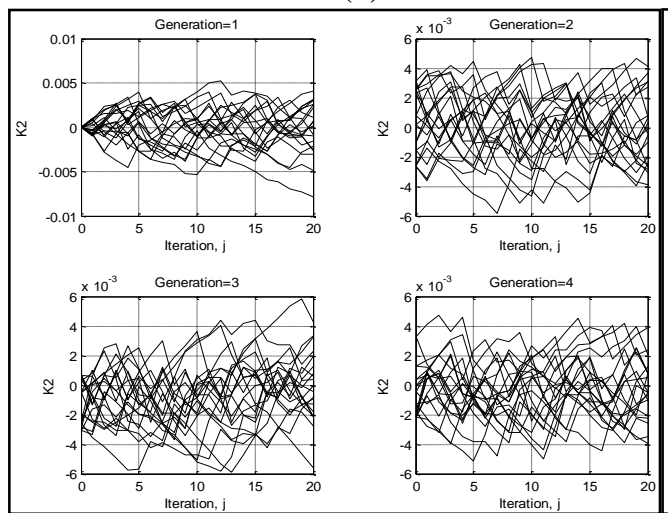

(c)
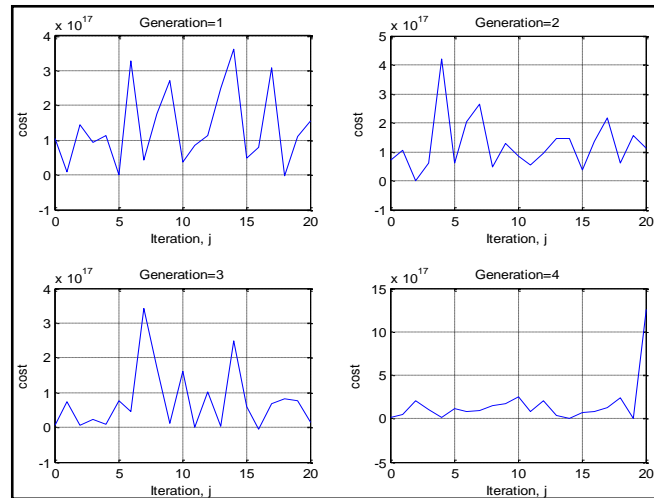

(e)
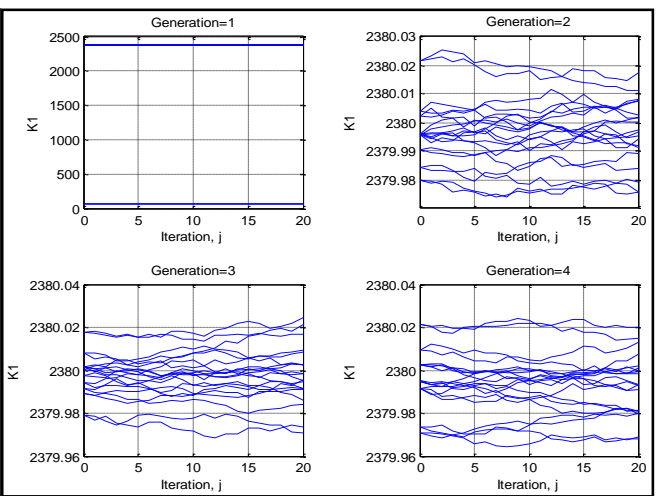

(b)
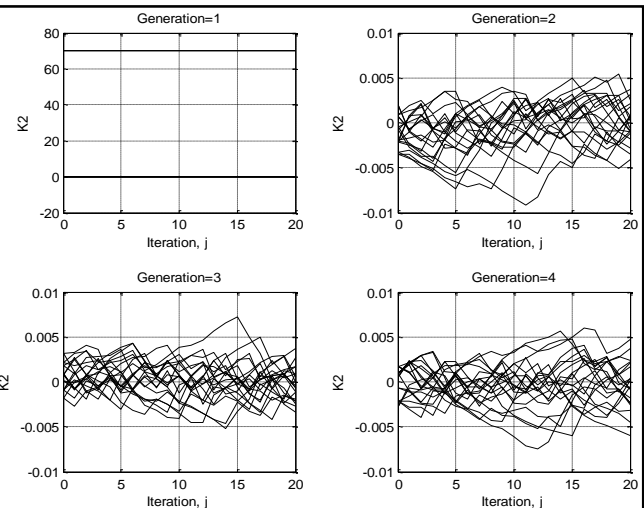

(d)
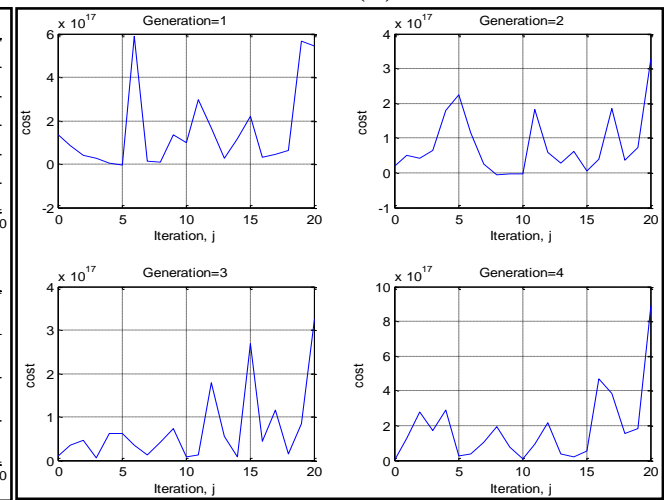

(f)

Figure 3. Bacteria Trajectories and Average Cost Plot for Tuning the Controller Parameters of the Armature Control Method

(a), (b) first \& second elimination/dispersal event for $\left(K_{1}\right)$ respectively

(c),(d) first \& second elimination/dispersal event for $\left(K_{2}\right)$ respectively

(e), (f) average cost plot for first \& second elimination/dispersal event respectively 


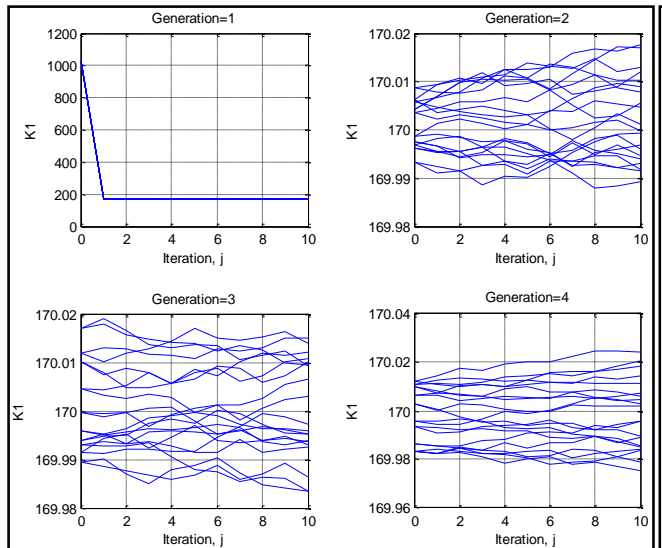

(a)
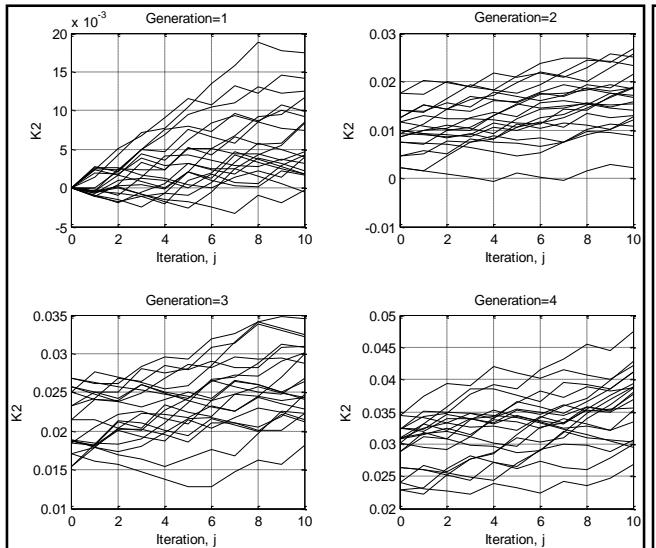

(c)
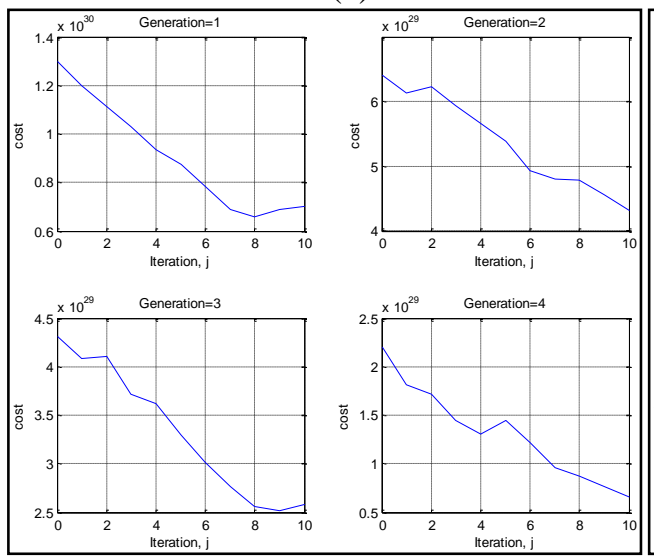

(e)

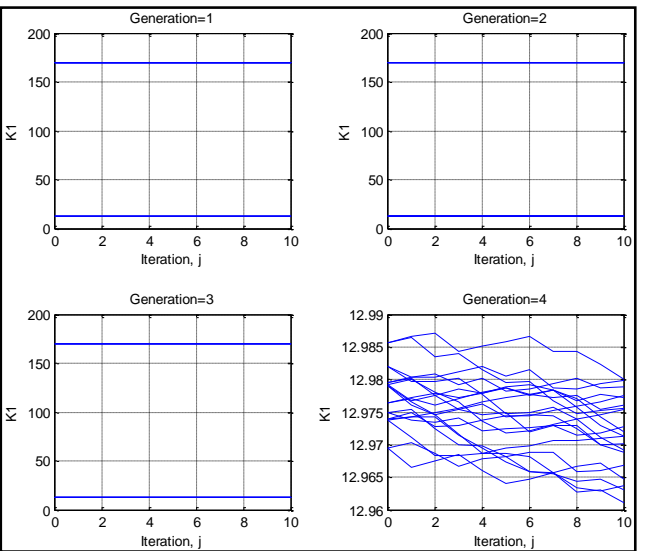

(b)
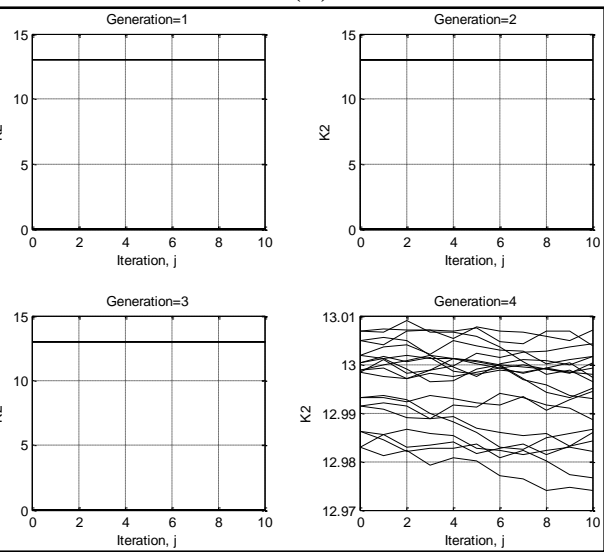

(d)
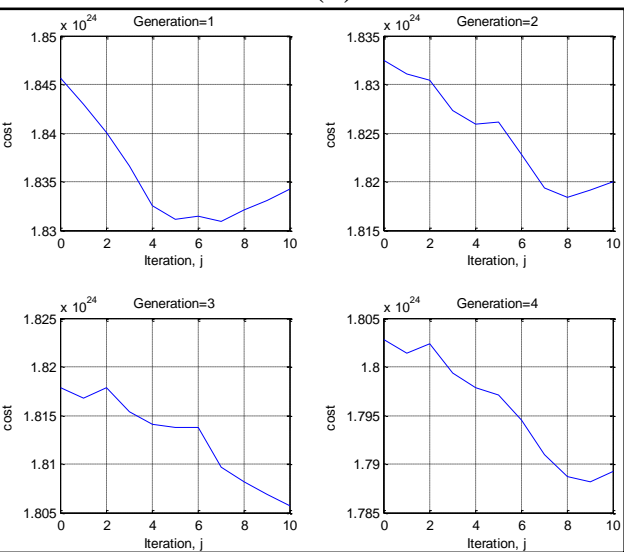

(f)

Figure 4. Bacteria Trajectories and Average Cost Plot for Tuning the Controller Parameters of the Field Control Method

(a), (b) first \& second elimination/dispersal event for $\left(K_{1}\right)$ respectively

(c),(d) first \& second elimination/dispersal event for $\left(K_{2}\right)$ respectively

(e), (f) average cost plot for first \& second elimination/dispersal event respectively

Figure 5, show currents, voltages, torque and speed of the SEDM for both armature and field control methods. Both control methods are with state feedback controller tuned by BFO technique and the motor are loading with different loads ranging from no-load to full-load. 


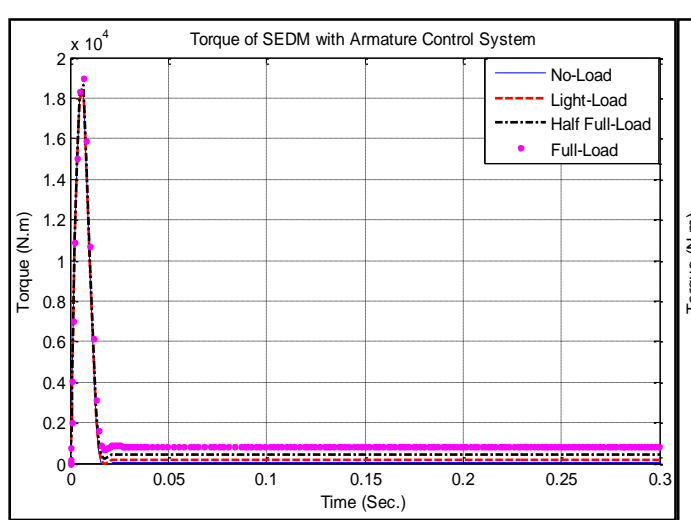

(a)

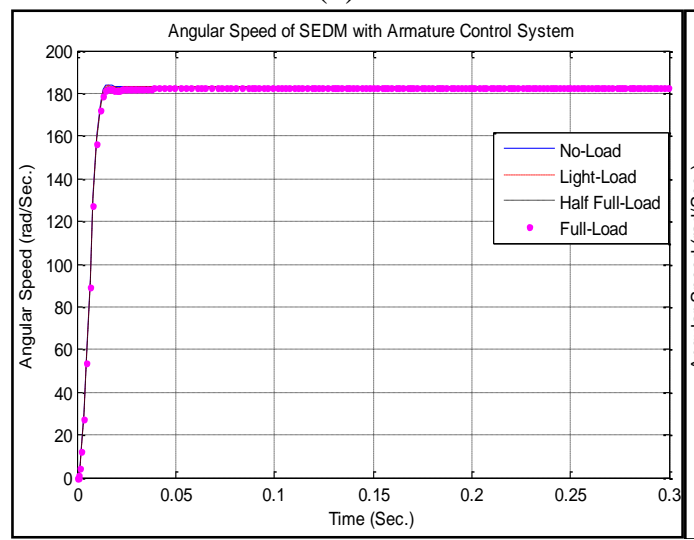

(c)

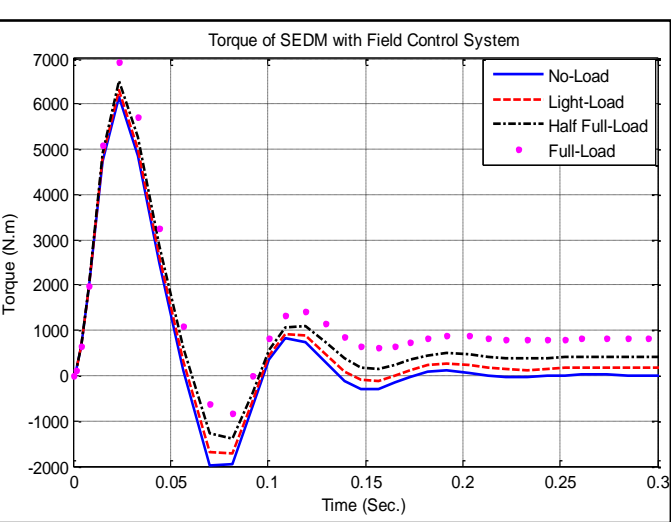

(b)

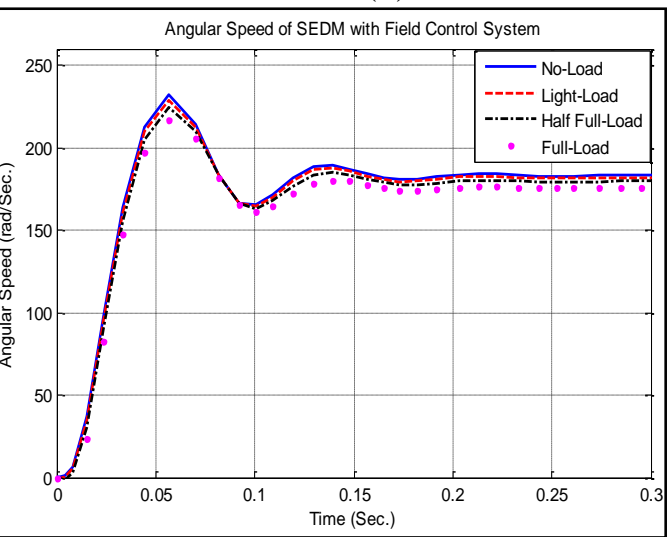

(d)

Figure 5. Time Responses of SEDM for Armature \& Field Control at Different Loads

(a) Torque (N.m) for armature control system

(b) Torque (N.m) for field control system

(c) Angular speed (rad/sec.) for armature control system

(d) Angular speed (rad/sec.) for field control system

The time response specifications of SEDM speed response are listed in Table 4, for armature and field control systems with different loading conditions.

Table 4. Time Response Specifications

\begin{tabular}{|l|c|c|c|c|}
\hline & $\begin{array}{c}\text { Rise time } \\
(\mathrm{m} . S e c .)\end{array}$ & $\begin{array}{c}\text { Peak time } \\
(\mathrm{m} . S e c .)\end{array}$ & $\begin{array}{c}\text { Overshoot } \\
(\mathrm{rad} / \text { Sec. })\end{array}$ & $\begin{array}{c}\text { Settling time } \\
(\mathrm{m} . \text { Sec. })\end{array}$ \\
\hline \multicolumn{5}{|c|}{ SEDM at no-load } \\
\hline Armature control method & 7.94 & 16 & 184.084 & 11.7 \\
\hline Field control method & 23.5 & 56.5 & 232 & 111 \\
\hline \multicolumn{5}{|c|}{ SEDM at light-load } \\
\hline Armature control method & 8.01 & 16 & 183.634 & 11.8 \\
\hline Field control method & 23.5 & 56.5 & 229 & 113 \\
\hline \multicolumn{5}{|c|}{ SEDM at half full-load } \\
\hline Armature control method & 8.06 & 16 & 182.9588 & 12 \\
\hline Field control method & 23.7 & 56.5 & 224 & 116 \\
\hline \multicolumn{5}{|c|}{ SEDM at full-load } \\
\hline Armature control method & 8.17 & 16 & 181.8334 & 12.4 \\
\hline Field control method & 24.1 & 56.5 & 217 & 123 \\
\hline
\end{tabular}


Armature control has the advantage of controlling the armature current swiftly, by adjusting the applied voltage. The response is determined by the armature time constant, which has a very low value. The large time constant of the field causes the response of a field-controlled dc motor drive to be slow and sluggish. Armature control is limited in speed by the limited magnitude of the available dc supply voltage and armature winding insulation. If the supply dc voltage is varied from zero to its nominal value, then the speed can be controlled from zero to nominal or rated value. Therefore, armature control is suitable for rated speed and speeds lower than rated speed while field control is suitable for speeds greater than the rated speed.

\section{Conclusions}

In this work, BFO technique has been used to design state feedback controllers for armature and field control methods for speed control of SEDM. BFO is used to find optimal controller parameters $\left(\mathrm{K}_{1}\right.$ and $\left.\mathrm{K}_{2}\right)$. From simulation results the following tips can be concluded:

1) The BFO technique is robust and efficient for controllers tuning.

2) BFO required less execution time, due to the small numbers of bacterial foraging parameters and fast convergence ability.

3) $\mathrm{BFO}$ has fast convergence due to the bacteria social behavior for finding nutrient and it is efficient tool for optimization problems.

4) The armature and field control methods are robust for wide range of loading conditions.

5) $\mathrm{BFO}$ technique has potential to be useful for other practical optimization problems (e.g., engineering design, online distributed optimization in distributed computing, and cooperative control) as social foraging models work very well in such environments.

6) Armature control is suitable for rated speed and speeds lower than rated speed while field control is suitable for speeds greater than the rated speed.

\section{References}

[1] H. Q. Hameed, "PSO-FL Controller of Separately Excited DC Motor", Eng. \& Tech. Journal,Vol.31, Part(A), No.11, (2013).

[2] A. Gaaloul and F. M. Sahli, "Nonlinear Observers-Based State Feedback Control: Application to an Inverted Pendulum", J. Automation \& Systems Engineering, (2008).

[3] A. J. Mohammed, " Speed Control for Separately Excited DC Motor Drive (SEDM) Based on Adaptive Neuro-Fuzzy Logic Controller", Eng. \& Tech. Journal,Vol.31, No.2, (2013)

[4] C. LIU, B. LI, X. YANG, "Fuzzy Logic Controller Design Based on Genetic Algorithm for DC Motor", IEEE 978-1-4577-0321-8/11/\$26.00 @ (2011).

[5] V. Tipsuwanpom, A. Numsomran, N. Klinsmitth, S. Gulphanich, "Separately Excited DC Motor Drive With Fuzzy Self-Organizing", International Conference on Control, Automation and Systems 2007 Oct. 17-20, in COEX, Seoul, Korea, (2007).

[6] B. K. Panigrahi,Y. Shi, and M. Lim, "Handbook of Swarm Intelligence", Springer-Verlag Berlin Heidelberg, (2011).

[7] V. Gazi and K. M. Passino, "Swarm Stability and Optimization", Springer Science + Business Media B.V.(2011).

[8] S. S. Patnaik and A. K. Panda, "Particle Swarm Optimization and Bacterial Foraging Optimization Techniques for Optimal Current Harmonic Mitigation by Employing Active Power Filter", Hindawi Publishing Corporation Applied Computational Intelligence and Soft Computing Volume (2012).

[9] X. Yan, Y. Zhu, H. Zhang, H. Chen, and B. Niu, "An Adaptive Bacterial Foraging Optimization Algorithm with Lifecycle and Social Learning", Hindawi Publishing Corporation Discrete Dynamics in Nature and Society Volume (2012). 
International Journal of $u-$ and $e-$ Service, Science and Technology Vol.8, No.2 (2015) 